\title{
REVIEW ABOUT RADIOPHARMACEUTICALS: PREPARATION, RADIOACTIVITY, AND APPLICATIONS
}

\section{SHOMOKH ALSHAREF ${ }^{1}$, MASHAEL ALANAZI ${ }^{1}$, FATIMAH ALHARTHI ${ }^{1}$, DANA QANDIL ${ }^{1}$, MONA QUSHAWY ${ }^{2,3}$}

1Pharm D Program, Faculty of Pharmacy, University of Tabuk, Tabuk, Saudi Arabia, ${ }^{2}$ Department of Pharmaceutics, Faculty of Pharmacy, University of Tabuk, Tabuk 71491, Saudi Arabia, ${ }^{3}$ Department of Pharmaceutics, Faculty of Pharmacy, Sinai University, Alarish, North Sinai 45511, Egypt

Email: mqushawy@ut.edu.sa

Received: 15 Feb 2020, Revised and Accepted: 12 Mar 2020

\begin{abstract}
In the recent few decades, there was a growth in the field of radioactive medicinal agents called radiopharmaceuticals. Radiopharmaceuticals are consisting of radioactive materials called radioisotopes. Radiopharmaceuticals were recently used in both therapeutic and diagnostic purposes. More than 100 radioactive substances are used in nuclear medicine. According to the decay of radioactive substances, there are three types of radioactive decays, alpha particles, beta particles, and gamma radiations. Alpha particles consist of two protons and two neutrons with large mass and charge so it has no penetration power into the skin and has a destructive effect. Beta particles have less charge and less mass so, they can penetrate the tissue and have a less destructive effect than alpha particles and can be used in therapy. Gamma radiations have no mass or charge so they can penetrate the deep tissue of organs so used in diagnosis by imaging using a gamma camera. The radiopharmaceuticals were established in the diagnostic purpose and treatment of several diseases as thyroid gland cancer, hyperthyroidism, bone pain metastasis, kidney dysfunction, and myocardial and cerebral perfusion. The radioactive substance can also be used in the sterilization of thermo-labile substances as syringes, catheters, vitamins, hormones, and surgical dressing. The field of nuclear medicine has several advantages as localization of tumors, safe diagnosis, no accumulation of radiation, and high therapeutic efficacy. Nowadays, the branch of nuclear pharmacy is directed to introduce new radioactive pharmaceutical agents which will be important and effective in the treatment of cancer. The growth in the field of radiopharmaceuticals is important to help millions of patients suffering from tumors all over the world. The data of this review were collected by searching in Google Scholar and PubMed using the following keywords.
\end{abstract}

Keywords: Radiopharmaceuticals, Thyroid gland, Bone pain, Diagnosis, Therapeutic effect, Tumors, Myocardial and cerebral perfusion

(C) 2020 The Authors. Published by Innovare Academic Sciences Pvt Ltd. This is an open access article under the CC BY license (http://creativecommons.org/licenses/by/4.0/) DOI: http://dx.doi.org/10.22159/ijap.2020v12i3.37150. Journal homepage: https://innovareacademics.in/journals/index.php/ijap

\section{INTRODUCTION}

Radiopharmaceuticals are radioactive substances used in the fields of diagnosis and therapy [1]. In 1978, the board of pharmaceutical specialties introduced the nuclear pharmacy as a specialty in pharmacy, which concerns the safe and effective application of radioactive agents [2].

There are more than 100 radioactive agents which used for therapeutic purpose as in localization of tumors, hyperthyroidism [3], toxic diffuse goiter [4], bone pain related to skeletal metastasis [5], cerebral perfusion [6]. Also, these radioactive drugs used in diagnosis as infection imaging and kidney dysfunction [7].

There are a wide variety of radiopharmaceuticals having different mechanisms of targeting and different forms and also different route of administration may be given in simple salt form or attached to more complex molecules [8]. There are different rout of administration for radiopharmaceuticals, may be given orally parentally or installed into the eyes.

Most of the radiopharmaceuticals (about 95\%) are used for diagnostic purpose while the remaining are used in therapy [9]. Radiopharmaceuticals are different than the traditional drugs in being there is no pharmacological effect [10].

The radiopharmaceuticals provide a non-invasive mechanism for targeting the therapeutic radiations with low side effects [11]. Also, in case of diagnosis, radioactive drugs represent non-invasive imaging agents which give information about the structure and function of diseased organs or tissue [12].

The aim of this review is to introduce valuable information about the safe and effective use of radiopharmaceuticals in the fields of diagnosis and therapy.

\section{Radiopharmaceuticals}

The radiopharmaceuticals are radioactive substances which disintegrate instantaneously by emitting radiations [13]. The radioactive nuclides are like normal nuclides having the same number of protons with different numbers of neutrons. The emitted radiation may be in the form of alpha, beta, and gamma radiation [14]. The dose of radiopharmaceuticals is dispensed to the patient in the form of Curie, which equals to $3.7 \times 10^{10}$ decomposition per second [15].

The radioactive substances are different in the half-life, which defined as the time needed to the disintegration of active substances to half the initial concentration [16]. As represented in table (1), an example of the most important radiopharmaceuticals and their half-life's.

Radiopharmaceuticals can be divided into four categories

\section{- Radiopharmaceutical preparation}

It is a preparation which contains radionuclide and ready to use by humans. The Presence of the radionuclide is very important, making the preparation useful in the diagnosis or therapy [28].

\section{- Radionuclide generator}

It is the system that allows separation of a daughter radionuclide (short half-life) from a parent radionuclide (long half-life) by elution or by other means to allow the use of later in the production of a radiopharmaceutical preparation [29].

\section{- Radiopharmaceutical precursor}

A radionuclide produced for the radiolabelling process with a resultant radiopharmaceutical preparation [30].

\section{- Kit for radiopharmaceutical preparation}

The kits intended for preparation of the radiopharmaceutical preparation are usually in the form of sterilized and validated vial containing the non-radionuclide components. The radionuclide is added to the vial just before use. After the addition of the appropriate radionuclide, additional steps may be needed as boiling, filtration, and buffering. The prepared radiopharmaceuticals must be used within $12 \mathrm{~h}$ after preparation [31]. 
Table 1: Different types of radionuclide and their halve life's

\begin{tabular}{|c|c|c|}
\hline Radionuclide & Half-life & References \\
\hline 99mTC (Technetium-99m) & 6.02 hour & [17] \\
\hline 131I (Iodine-131) & $8 \mathrm{~d}$ & {$[18]$} \\
\hline 18F (Fluorine-18) & $110 \mathrm{~min}$ & [19] \\
\hline 123I (Iodine-123) & $13.27 \mathrm{~h}$ & [20] \\
\hline${ }^{67} \mathrm{Ga}$ (Gallium-67) & $3.26 \mathrm{~d}$ & [21] \\
\hline${ }^{133}$ Xe (Xenon-133) & $5.24 \mathrm{~d}$ & {$[22]$} \\
\hline${ }^{201} \mathrm{Tl}$ (Thallium-201) & $3.04 \mathrm{~d}$ & {$[23]$} \\
\hline${ }^{89} \mathrm{Sr}$ (Strontium-89) & $50.53 \mathrm{~d}$ & {$[24]$} \\
\hline 125I (Iodine-125) & $59.41 \mathrm{~d}$ & {$[25]$} \\
\hline${ }^{57}$ Co (Cobalt-57) & $271.79 \mathrm{~d}$ & [26] \\
\hline${ }^{153} \mathrm{Sm}$ (Samarium-153) & $1.93 \mathrm{~d}$ & {$[27]$} \\
\hline
\end{tabular}

\section{Radionuclide production}

The radionuclides which intended for use in the radiopharmaceutical preparation can be prepared by one of the following methods.

\section{- Nuclear fission}

Nuclides with a high atomic number are characterized by being fissionable. The most common reaction is the fission of Uranium-235 by neutrons within the nuclear reactor. Anther examples of radionuclides prepared by this method are Iodine-131and Xenon133. The radionuclides prepared by this method must be carefully controlled to avoid radiation impurities [32].

\section{- Charged particle bombardment}

In this method, the cyclotrons are used to produce the radionuclide by bombarding the non-radionuclide with charged particles [29].

\section{- Neutron bombardment}

In this method, the radionuclides are prepared in the nuclear reactor by bombarding the non-radionuclide by neutrons [33]. Didi et al. studied the feasibility of the production of iodin-131 using dioxide of tellurium-130 under neutron activation [34].

\section{- Radionuclide generator systems}

This method is used for preparing the radionuclides with short halflife by separating the daughter radionuclide (short half-life) from the parent one (long half-life) by physical or chemical means using radionuclide generator system [29].

\section{Labeling and packaging of radiopharmaceuticals}

The label on the package should have the following information [35]:

- The name of the product and also the name of the added radionuclide.

- The code of the product.

- The name of the manufacturing company.

- The batch number.

- For liquid preparations, the total volume in the vial, and the total concentration of radionuclide within the vial or the concentration per milliliter at the date and time of the manufacturing.

- $\quad$ For solid preparations (lyophilized powder), the total amount of radionuclide at the date and time of the manufacturing.

- For capsules, the total number of capsules in the package and also the amount of radionuclide in each capsule.

- $\quad$ All ingredients should be mentioned in the label.

- The route of administration and the expiration date.

- $\quad$ Specific storage conditions.

\section{Packaging}

The packing and labeling materials should be suitable for the condition of the product [36].

\section{The package leaflets}

Package leaflets of the kits or the product should include:

- The name and the use of the radioactive product.

- The name of all ingredients in the product.

- The name of the manufacturer of the kits and the address.

- The method of preparation of radiopharmaceutical from the kits and the Shelf-life of the prepared radiopharmaceutical.

- The route of administration, the pharmacological and toxicological effect of the prepared radiopharmaceutical and also the route of elimination from the body.

- The dose of radioactive substance from the prepared radiopharmaceutical.

- $\quad$ The Precautions which should be considered by the patient and the nuclear pharmacist during administration and the preparation of the product.

- The precautions which should be taken in consideration for the disposal of the container and its unused contents.

- The recommended dose of the prepared radiopharmaceuticals.

\section{Storage of radiopharmaceuticals}

The international standard guidelines for the storage of radioactive substances should be strictly applied [35]. The prepared radiopharmaceuticals should be stored in a well-closed container in a sufficiently shielded place to protect personnel from exposure to radiation.

\section{Radioactivity}

As shown in fig. (1), the different types of radioactive decays, which include alpha, beta, and gamma. The difference between the different types of radioactive decays is represented in table (2).

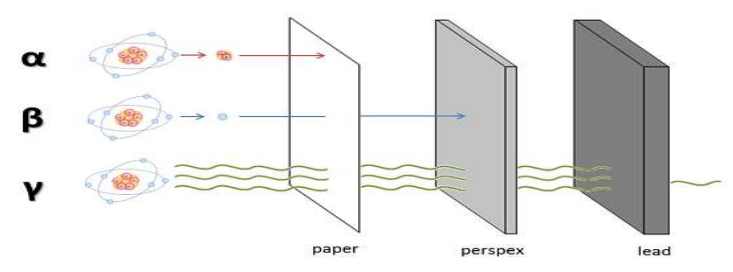

Fig. 1: Types of radioactivity: alpha, beta, and gamma decay [37]

\section{$>$ Alpha particle}

Alpha particles as helium nucleus consisting of two protons and two neutrons, which means that when the radionuclide decay and emit alpha particle, its atomic number will be decreased by 2 and also the atomic mass decreased by 4 . The alpha particles are heavy with high mass and slow so, they have low penetration power, which allows them to be stopped by a sheet of paper [38]. Due to the high mass of 
the alpha particles, they can't penetrate the outer layer of the skin when the body exposed to it and not cause a hazard's effect. While when the alpha particle emitters are inhaled, ingested or injected, the alpha particles cause a serious hazard effect on the internal organs due to the high charge of the alpha particles.

\section{$>$ Beta particle}

The beta particles resemble the electron in the mass and charge, which indicates that they have a very small mass in comparison to protons or neutrons. Beta particles may be of negative charge (negatron) or positive charge (positron). Due to the low mass of the beta particles, they have penetration power higher than the alpha particle which allows them to penetrate the sheet of paper but stopped by an aluminum sheet. Being charged, the beta particle has a destructive effect on the organs but less than alpha particles so, they can be used in therapy especially for the destruction of the tumor tissue [39].

\section{$>$ Gamma radiation}

The gamma radiations are emitted from the radioactive nuclide in the form of photons, not particles that means that they haven't a mass or charge. The radionuclides are decayed in the form of gamma radiations, the process not accompanied by any change in the atomic number or the atomic mass. Being radiation, the gamma rays have no mass so have high penetration power more the beta particles. Due to the absence of the charge, the gamma radiations have no destructive effect so, can be used for diagnosis. Technetium-99m is an example of a radionuclide which decayed in form of gamma radiation [39].

Table 2: Different types of radioactive decays of radiopharmaceuticals

\begin{tabular}{|c|c|c|c|c|}
\hline Types of decay & Alpha $(\alpha)$ & Beta $(\beta)$ & Gamma $(\gamma)$ & Reference \\
\hline Structure and origin & $\begin{array}{l}\text { Like helium nucleus emitted from the } \\
\text { radionuclide }\end{array}$ & $\begin{array}{l}\text { Like electron emitted from the } \\
\text { radionuclide }\end{array}$ & $\begin{array}{l}\text { Like waves emitted } \\
\text { from the radionuclide }\end{array}$ & {$[40]$} \\
\hline Charge & $\alpha^{2+}$ & $\beta-$ or $\beta+$ & Zero & [39] \\
\hline Mass & 4 & $1 / 1836$ & Zero & [39] \\
\hline $\begin{array}{l}\text { Ionization degree in } \\
\text { the human body }\end{array}$ & $\begin{array}{l}\text { Highly ionized so cause a destructive } \\
\text { effect and can't be used in nuclear } \\
\text { medicine }\end{array}$ & $\begin{array}{l}\text { Less than alpha particle can't be } \\
\text { used for diagnosis but used for } \\
\text { therapy }\end{array}$ & $\begin{array}{l}\text { No ionization so can be } \\
\text { used in imaging }\end{array}$ & [40] \\
\hline $\begin{array}{l}\text { Suitability for nuclear } \\
\text { imaging }\end{array}$ & Not suitable & Not suitable & Highly suitable & [39] \\
\hline
\end{tabular}

\section{The nuclear medicine}

Radiopharmaceuticals are pharmaceutical preparations that contain radioactive substances and radiolabel substances to be used either in diagnosis or therapy.

The Society of Nuclear Medicine, state that 20 million nuclear medicine procedures are carried out in the United States every year.
These procedures are done using the prepared radiopharmaceuticals and the imaging equipment for the diagnosis of a different disease or in treatment targets [41].

\section{Advantages and disadvantages of nuclear medicine}

Advantages of nuclear medicine

As shown in fig. (2), nuclear medicine has several advantages

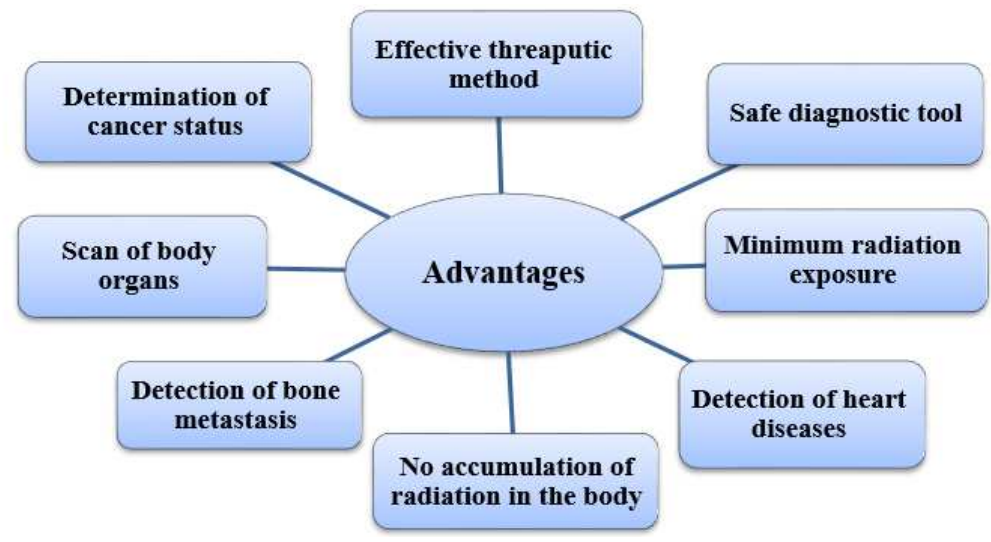

Fig. 2: The advantages of nuclear medicine

\section{- Providing information about the function and anatomy of the body}

The tests of nuclear medicine give complete information about the functions and anatomy of body organs. It represents a useful tool for the physician to determine the case of the patient and the best treatment. From the scan of the body, it is easy to decide on the tumor is malignant or benign, the physician can determine if surgery is required or not, and it is easily discovering the presence of disease before the appearance of the symptoms [42].

\section{- Determination of the cancer status}

Nuclear medicine is a useful tool for determining the status of the tumor. The physician can know if the tumor is metastasized or returned after size reduction [43].

\section{- Nuclear medicine is important in bone metastasis}

The bone pain source and the presence of bone cancer can be detected by nuclear medicine. Also, for an elderly patient, nuclear medicine serves as a tool for detecting the hidden features which resulted from osteoporosis [44, 45].

\section{- Nuclear medicine is important in heart disease (cardiology)}

Nuclear medicine is used by the cardiologist to recognize the causes of certain symptoms like the breath shortage and chest pain. Also, the nuclear medicine used for diagnosis of coronary artery disease caused by high cholesterol level, which causes the block of the blood and oxygen supply to the heart [46]. 
- Nuclear medicine minimizes the amount of radiation

The tissue and organ damage for patients can be done due to too much exposure to the radiation. While in the use of nuclear medicine, the amount of radiation is minimized to be as the usual $x$ ray [29].

- Nuclear medicine helps in accurate, painless, and safe diagnosis of several diseases

Nuclear medicine represents as accurate, non-invasive, safe, effective tool to manage the complex diagnosis as in case of patients suffering from many concurrent diseases. It gives a clear image and important information that can't be given with other diagnostic tests. It is important in the diagnosis of thyroid disease, bone Bain, and blood imbalance [29].

\section{- Nuclear medicine is important in therapy}

Some of the radioactive agents have therapeutic efficacy so they can be used by the physician in the treatment plan. They are used for the treatment of cases that can't be controlled by conventional drugs as in case of bone pain. Nuclear medicine also is useful in the case of thyroid cancer and hyperthyroidism [47].

- The radioactivity of radiopharmaceutical agents passes through the patient's body

After administration of the accurate dose of the radiopharmaceuticals, the gamma rays are emitted to give the therapeutic effect and the excess is passed through the body via stool and urine, so no accumulation of radiation inside the body due to radioactive decay [48].

\section{The disadvantages of nuclear medicine}

Nuclear medicine has several disadvantages as shown by a fig. (3)

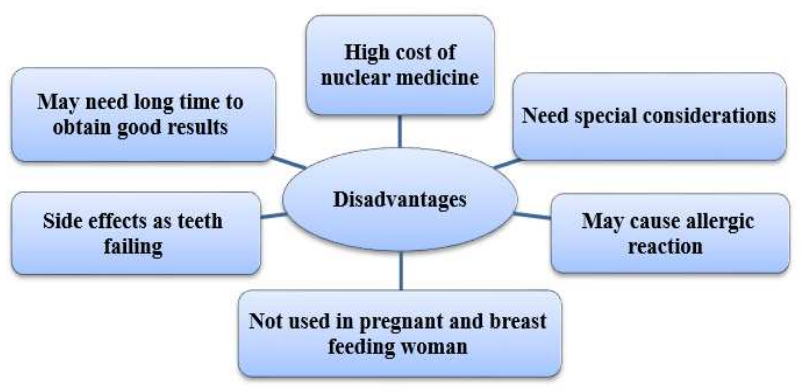

Fig. 3: The disadvantages of nuclear medicine

\section{- Nuclear medicine is not recommended for the pregnant and breastfeeding woman}

The unborn babies have great sensitivity to the radiation of radiopharmaceutical drugs than children and adults [49].

\section{- Nuclear medicine may cause an allergic reaction in some cases}

The allergic reaction accompanied to nuclear medicine is rare. It may occur for 1 every 400000 cases. The patient should speak with the physician about his history before stating nuclear medication, especially if the patient suffered from any medication allergy or have anaphylaxis shock in the past. The most popular side effects of radiotherapy are headache, dizziness, low blood pressure, and abnormal heart rate [50]

- Specific consideration should be followed before starting the nuclear medicine in some cases

A special construction should be followed by the patient before starting a nuclear medicine such as in the case of thyroid, heart, and gastrointestinal tract scan. In the thyroid scan, the patient should stop any medication for about 2-4 $\mathbf{w}$ before the nuclear medicine. In the case of heart examination, the patient should fast for at least $4 \mathbf{h}$ before nuclear medicine. In the case of the gastrointestinal system, the patient should undergo certain required premedication tests and be fasted for about $4 \mathrm{~h}$ before starting the nuclear medication [51].

\section{- The high cost of nuclear medication}

Most of the patients can't tolerate the therapy cost, so these patients resort to cover the cost of treatment by medical insurance or to be taking a grant from the government. The high cost of nuclear medicine is due to the medical instruments used in this purpose [52].

\section{- Side effects related to nuclear medicine}

The exposure of the patient to the nuclear medication may lead to the teeth failing, dental braces and distortion around the mouth area [53].

\section{- Nuclear medicine may consume a long time}

When the patient receives a radiopharmaceutical agent, the imaging may be done after about 30-60 min, several hours, or several days to obtain good results. The time varies according to the decay time of the radiopharmaceutical agent to emit the radiations [54].

\section{Application of radiopharmaceuticals}

Radiopharmaceuticals have several applications as shown by a fig. (4).

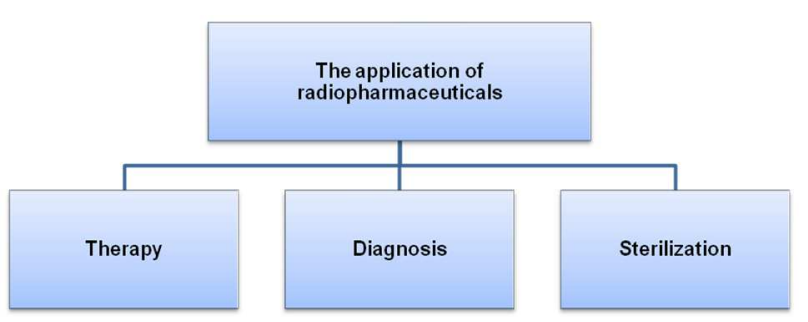

Fig. 4: The applications of radiopharmaceuticals

\section{A-The therapeutic application of radiopharmaceuticals}

The radiopharmaceutical preparations intended for therapeutic purposes are designed to deliver the radiolabeled molecules to specific diseased sites inside the body to allow the emission of charged beta particles in the target site to give therapeutic responses as in the case of tumors. As represented in table (3), some radiopharmaceuticals with their therapeutic applications.

The ideal properties of therapeutic radiopharmaceuticals are [9]:

- High uptake at a specific site

- Less activity in the blood

- No retention in any other tissue or organ

- Excretion through the renal pathway

The therapeutic radiopharmaceuticals are used in different fields as in cardiology for myocardial perfusion, oncology for tumors, and neurology for cerebral perfusion.

Application of radiopharmaceuticals in the treatment of hyperthyroidism and thyroid cancer

Hyperthyroidism is the elevated production of thyroid hormone from the thyroid gland, which resulted in a clinical case called thyrotoxicosis [55].

Oral administration of Iodine-131 has been a frequently accepted route for the treatment of malignant and benign thyroid disorder and hyperthyroidism [56].

Iodine-131 is a radioisotope with a half-life of $8 \mathrm{~d}$. It decays in the form of gamma rays and beta particles [57]. The therapeutic effect 
of Iodine-131 depends on the ability of iodine to concentrate in the thyroid gland [58].

The radiolabeled Iodine-131 can be administered as first-line treatment if the hyperthyroidism returns or not controlled after treatment with an anti-thyroid drug or after thyroid surgery [59].

The radiolabeled Iodine- 131 is selectively accumulated in the tissue of thyroid gland and decays by emission of alpha particle, which destroys the tumor tissue in case of thyroid cancer.

Radiolabeled Iodine-131 may be administered in oral dosage form (liquid or capsules) or parentally (intravenous injection) for patients having difficulty in swallowing or vomiting.

\section{Application of radiopharmaceuticals in the treatment of bone metastasis}

Bone metastasis is the most common type of pain in cancer patients. It reduces patient quality of life and linked with many complications, such as hypercalcemia, bone fractures, spinal cord compression [5]. Treatment is mainly palliative by using analgesic drugs, antiinflammatory drugs, radiotherapy and surgery [60].
Various radionuclides are used to provide analgesic treatment of bone metastases, including samarium-153 (Sm-153), phosphorus-32 (P-32) and strontium-89 (Sr-89) [10].

Samarium-153 is a radionuclide with 1.9 d half-life which can be used for diagnosis and treatment of bone metastasis due to the emission of both beta particle and gamma radiation [10]. Samarium153 has the ability to target the bone tumor, it goes to the source of cancer bone pain and emits the beta particles resulting in pain relief. In the majority of patients, pain relief occurs within the first week of therapy.

Phosphorus-32 used to suppress hyper proliferative cells. It emits beta particles with a physical half-life is $14.3 \mathrm{~d}$. It decays in the form of beta particles with a maximum energy of $1.71 \mathrm{MeV}$ allow it to be useful in case of bone metastasis [61].

Strontium-89 chloride is administered intravenously, it deacys and emits beta particles. The physical half-life of Strontium-89 is $51 \mathrm{~d}$. It has the ability to accumulate metastatic bone lesions in higher concentrations than in healthy normal bone. After intrsvenous injection, the Strontium-89 acts as calcium it selectively cleared from the blood and localized in the bone minerals [62].

Table 3: The therapeutic application of radionuclides

\begin{tabular}{|c|c|c|}
\hline Radionuclide & The therapeutic use & Reference \\
\hline Iodine-131, Ytrium-90 & Used for treatment of non-Hodgkins lymphoma & {$[63,64]$} \\
\hline Americum-241, Californium-252 & Used for treatment of cancers and tumors & {$[65,66]$} \\
\hline \multicolumn{3}{|l|}{ Cobalt-60, Gold-194 } \\
\hline Holmium-66 & Used for treatment of liver cancers & [10] \\
\hline Iodine-131 & $\begin{array}{l}\text { Used as antineoplastic, and for Grave' disease (hyperthyroidism and differentiated } \\
\text { thyroid cancer. }\end{array}$ & [67] \\
\hline Rhenium-186 & Used for relief the pain associated with bone metastasis & [68] \\
\hline Ytrium-90 & Used as cancer brachytherapy & [69] \\
\hline Samarium-153, Strontium-89 & Palliative treatment of bone metastasis & [70-72] \\
\hline \multicolumn{3}{|l|}{ Phosphorus-32 } \\
\hline Erbium-169, Ytrrium-90 & Relief of arthritis pain & [73] \\
\hline Samarium-153 & Pain relief in bone cancer, prostate and breast cancer & [70] \\
\hline Strontium-89 & Reduces pain in prostate and bone cancer & [74] \\
\hline
\end{tabular}

\section{B-The diagnostic application of radiopharmaceuticals}

The bodies' organs differ in their function. Throughout the study, the physicians identified the chemical substances which can be uptaken and absorbed by each organ. For example, the thyroid gland selectively uptake Iodine, the brain uptake the glucose, and the bones uptake the calcium. This idea is used in the case of radiopharmaceuticals, where the radioisotope when entering the body is selectively uptaken by certain organs. The ideal diagnostic radionuclide is that with short half-life and decay by emission of gamma radiation. Technetium-99 $\mathrm{m}$ is considered the ideal diagnostic radionuclide as it has a short half-life $(6 \mathrm{~h})$, decay by emission of gamma radiation only, and efficiently detected by gamma camera [75].
As represented in table (4), diagnostic radiopharmaceuticals can be used to detect different diseases and image different organs.

Curtis et al. used radioactive fluorine-18 for early diagnosis of Alzheimer's disease [76]. Vente et al. used radioactive Holmium-166 to detect and diagnose liver cancer [77]. Maxon et al. used Radioiodene-131 in the diagnosis of metastatic thyroid cancer [78]. Mandel, et al. used iodine-123 in the scanning of thyroid remnants in patients with differentiated thyroid cancer [79]. Elmotaleb et al. prepared radioiodopropranol using iodin-125 for lung perfusion scan [80]. Visakh et al. estimated the amount of radiation that entered the thyroid region during a computed tomography (CT) brain scan [81].

Table 4: The diagnostic application of radionuclides

\begin{tabular}{ll}
\hline Radionuclide & The diagnostic use \\
\hline Technetium-99 $\mathrm{m}$ & Used in diagnosing of cardiac amyloidosis \\
Chromium-51 & Used in diagnosis of pernicious anemia \\
Fluorine-18 & Used in positron emission tomography to assess alternations in glucose metabolism in brain and cancer \\
Holmium-166 & Used in the diagnosis of liver cancer \\
Iodine-125 & Used in diagnosis and evaluation of the glomerular filtration rate of kidneys \\
Gallium-67 & Used in tumors imaging \\
Potassium-42 & Used in determination of exchangeable potassium in coronary blood flow \\
Rubidium-86 & Used in determination of myocardial blood flow \\
Iodine-131 & Used in studying the function of the thyroid gland \\
Selenium-75 & Used to study the production of digestive enzymes \\
Sodium-24 & Used to study sodium exchange \\
Xenon-133 & Used to study the pulmonary ventilation \\
Thallium-201 & Used to diagnose coronary artery disease, death of heart muscle, and the location of lymphoma (low grade) \\
Strontium-92 & Used in imaging of neuroendocrine tumors \\
\hline
\end{tabular}




\section{C-Application of radioactive substances in sterilization}

The thermo-labile substances are sterilized by radiation. The radioisotopes are used for this purpose. The thermo-sensitive substances include hormones, vitamins, antibiotics, surgical dressings, and disposable syringes. Cobalt-60 is an example of radioisotopes that decay by gamma radiation and used for sterilization of the thermo-labile substances [93].

\section{CONCLUSION}

The authors concluded that there are a lot of radioactive substances that have a great effect on diagnosis and therapy. Nowadays, the branch of nuclear pharmacy is directed to introduce new radioactive pharmaceutical agents which will be important and effective in the treatment of cancer. The growth in the field of radiopharmaceuticals is important to help millions of patients suffering from tumors all over the world.

\section{FUNDING}

Nil

\section{AUTHOR CONTRIBUTIONS}

All authors contributed equally to this work

\section{CONFLICT OF INTERESTS}

The authors disclose that no conflicting interests associated with the manuscript exist.

\section{REFERENCES}

1. Nadugopal B, Swain SS, Ojha SK, Meher CP. Impact of radiopharmaceuticals in the healthcare system. PharmaTutor 2017;5:23-31.

2. Heske SM, Hladik WB, Laven DL, Kavula MP. Status of radiologic pharmacy education in colleges of pharmacy. Am J Pharm Educ 1996;60:152-61.

3. Skanjeti A, Miranti A, Yabar GMD, Bianciotto D, Trevisiol E, Stasi M, et al. A simple and accurate dosimetry protocol to estimate activity for hyperthyroidism treatment. Nucl Med Rev 2015;18:13-8.

4. Nakagawa Y, Mori K, Hoshikawa S, Ozaki H, Ito S, Yoshida K. Development of subclinical hyperthyroidism due to Graves' disease in a hypothyroid woman who had undergone hemithyroidectomy for adenomatous goiter and radiotherapy for nasopharyngeal cancer. Endocr J 2007;54:35-7.

5. Paes FM, Serafini AN. Systemic metabolic radiopharmaceutical therapy in the treatment of metastatic bone pain. In: Seminars in nuclear medicine. Elsevier; 2010. p. 89-104.

6. Paes FM, Ernani V, Hosein P, Serafini AN. Radiopharmaceuticals: when and how to use them to treat metastatic bone pain. J Support Oncol 2011;9:197-205.

7. Taylor AT. Radionuclides in nephrourology, part 1: radiopharmaceuticals, quality control, and quantitative indices. J Nucl Med 2014;55:608-15.

8. Pauwels EK, McCready VR, Stoot JH, van Deurzen DF. The mechanism of accumulation of tumor-localizing radiopharmaceuticals. Eur J Nucl Med 1998;25:277-305.

9. Volkert WA, Hoffman TJ. Therapeutic radiopharmaceuticals. Chem Rev 1999;99:2269-92.

10. Dar M, Masoodi M, Farooq S. Medical uses of radiopharmaceuticals. PharmaTutor 2015;3:24-9.

11. Jalilian AR, Beiki D, Hassanzadeh Rad A, Eftekhari A, Geramifar P, Eftekhari M. Production and clinical applications of radiopharmaceuticals and medical radioisotopes in Iran. In: seminars in nuclear medicine. Elsevier; 2016. p. 340-58.

12. Ferro Flores G, E Ocampo Garcia B, Melendez Alafort L. Development of specific radiopharmaceuticals for infection imaging by targeting infectious micro-organisms. Curr Pharm Des 2012;18:1098-106.

13. Kost SD, Dewaraja YK, Abramson RG, Stabin MG. VIDA: a voxelbased dosimetry method for targeted radionuclide therapy using geant4. Cancer Biother Radiopharm 2015;30:16-26.

14. Del Guerra A, Panetta D. Fundamentals of natural and artificial radioactivity and interaction of ionizing radiations with the matter. In: Nuclear Medicine Textbook. Springer; 2019. p. 3-19.
15. Dobrescu L, Stanciu S, Pleșca C, Ropot A. Towards an integrated medical system for radiological medical imaging investigations. Res J Med Med Sci 2017;120:5.

16. Radvanyi P, Villain J. The discovery of radioactivity. Comptes Rendus Phys 2017;18:544-50.

17. Bruce Sodee D. The evaluation of metastatic thyroid carcinoma with technetium-99m pertechnetate. Radiology 1967;88:145-7.

18. Tjuvajev JG, Macapinlac HA, Daghighian F, Scott AM, Ginos JZ, Finn RD, et al. Imaging of brain tumor proliferative activity with iodine-131-iododeoxyuridine. J Nucl Med 1994;35:1407-17.

19. Gu X, Jiang M, Pan D, Cai G, Zhang R, Zhou Y, et al. Preliminary evaluation of novel 18F-AlF-NOTA-IF7 as a tumor imaging agent. J Radioanal Nucl Chem 2016;308:851-6.

20. Hupf HB, Eldridge JS, Beaver JE. Production of Iodine-123 for medical applications. Int J Appl Radiat Isot 1968;19:345-51.

21. Smith Jones PM, Stolz B, Bruns C, Albert R, Reist HW, Fridrich R, et al. Gallium-67/gallium-68-[DFO]-octreotide-a potential radiopharmaceutical for PET imaging of somatostatin receptorpositive tumors: synthesis and radiolabeling in vitro and preliminary in vivo studies. J Nucl Med 1994;35:317-25.

22. Stohl A, Seibert P, Wotawa G, Arnold D, Burkhart JF, Eckhardt S, et al. Xenon-133 and caesium-137 releases into the atmosphere from the fukushima dai-ichi nuclear power plant: determination of the source term, atmospheric dispersion, and deposition. Atmospheric Chem Phys 2012;12:2313-43.

23. Miyagawa M, Kumano S, Sekiya M, Watanabe K, Akutzu H, Imachi $\mathrm{T}$, et al. Thallium-201 myocardial tomography with intravenous infusion of adenosine triphosphate in the diagnosis of coronary artery disease. J Am Coll Cardiol 1995;26:1196-201.

24. Robinson RG, Preston DF, Spicer JA, Baxter KG. Radionuclide therapy of intractable bone pain: emphasis on strontium-89. Semin Nucl Med 1992;22:28-32.

25. Whitmore Willet F, Hilaris Basil, Grabstald Harry. Retropubic implantation of iodine 125 in the treatment of prostatic cancer. J Urol 1972;108:918-20.

26. Van de Poll MC, Versluis A, Rasker JJ, Jurjens H, Woldring MG. Labelling of bleomycin with cobalt-57, indium-111, technetium-99m, mercury-197, lead-203, and copper-67. Nuklearmedizin 1976;15:86-90.

27. Singh A, Holmes RA, Farhangi M, Volkert WA, Williams A, Stringham LM, et al. Human pharmacokinetics of samarium153 EDTMP in metastatic cancer. J Nucl Med 1989;30:1814-8.

28. Adam MJ, Wilbur DS. Radiohalogens for imaging and therapy. Chem Soc Rev 2005;34:153-63.

29. Willowson KP. Production of radionuclides for clinical nuclear medicine. Eur J Phys 2019;40:043001.

30. Blower JE, Cooper MS, Imberti C, Ma MT, Marshall C, Young JD, et al. The radiopharmaceutical chemistry of the radionuclides of gallium and indium. In: radiopharmaceutical chemistry. Springer; 2019. p. 255-71.

31. Eppard E, Wuttke M, Nicodemus PL, Rösch F. Ethanol-based postprocessing of generator-derived 68Ga toward kit-type preparation of 68Ga-radiopharmaceuticals. J Nucl Med 2014;55:1023-8.

32. Reed BC. An examination of the potential fission-bomb weaponizability of nuclides other than $235 \mathrm{U}$ and $239 \mathrm{Pu}$. Am J Phys 2017;85:38-44.

33. Qaim SM, Spahn I, Scholten B, Neumaier B. Uses of alpha particles, especially in nuclear reaction studies and medical radionuclide production. Radiochim Acta 2016;104:601-24.

34. Abdessamad Didi, Ahmed Dadouch, Hassane El Bekkouri. Feasibility study for production of Iodine-131 using dioxide of tellurium-130. Int J Pharm Pharm Sci 2016;8:e331.

35. Debnath S, Babu MN. Radiopharmaceuticals and their therapeutic applications in the health care system. Asian J Res Pharm Sci 2015;5:221-6.

36. Hung JC, Ponto JA, Gadient KR, Frie JA, Aksamit CM, Enquist CL, et al. Deficiencies of product labeling directions for the preparation of radiopharmaceuticals. J Am Pharm Assoc 2004;44:30-5.

37. Parigger CG, Dackman M, Hornkohl JO. Time-resolved spectroscopy measurements of hydrogen-alpha,-beta, and gamma emissions. Appl Opt 2008;47:G1-G6.

38. Lassmann M, Eberlein U. Targeted alpha-particle therapy: imaging, dosimetry, and radiation protection. Ann ICRP 2018;47:187-95. 
39. Maulany GJ, Manggau FX, Jayadi J, Waremra RS, Fenanlampir CA. Radiation detection of alfa, beta, and gamma rays with geiger muller detector. Int J Mech Eng Technol 2018;9:21-7.

40. Magill J, Galy J. Radioactivity radionuclides radiation. Vol. 1. Springer Science and Business Media; 2004.

41. Blankenberg FG, Strauss HW. Nuclear medicine applications in molecular imaging. J Magn Reson Imaging Off J Int Soc Magn Reson Med 2002;16:352-61.

42. Hughes DK. Nuclear medicine and infection detection: the relative effectiveness of imaging with 111In-oxine-, 99mTc-HMPAO-, and 99mTc-stannous fluoride colloid-labeled leukocytes and with 67Ga-citrate. J Nucl Med Technol 2003;31:196-201.

43. Tryciecky EW, Gottschalk A, Ludema K. Oncologic imaging: interactions of nuclear medicine with CT and MRI using the bone scan as a model. In: Seminars in nuclear medicine. Elsevier; 1997. p. 142-51.

44. Vassiliou V, Andreopoulos D, Frangos S, Tselis N, Giannopoulou E, Lutz S. Bone metastases: assessment of therapeutic response through radiological and nuclear medicine imaging modalities. Clin Oncol 2011;23:632-45.

45. Love C, Palestro CJ. Nuclear medicine imaging of bone infections. Clin Radiol 2016;71:632-46.

46. Nakajima K, Matsumoto N, Kasai T, Matsuo S, Kiso K, Okuda K. Normal values and standardization of parameters in nuclear cardiology: Japanese Society of Nuclear Medicine working group database. Ann Nucl Med 2016;30:188-99.

47. Saha GB. Therapeutic uses of radiopharmaceuticals in nuclear medicine. In: Fundamentals of Nuclear Pharmacy. Springer; 2018. p. 373-83.

48. Loke KS, Padhy AK, Ng DC, Goh AS, Divgi C. Dosimetric considerations in radioimmunotherapy and systemic radionuclide therapies: a review. World J Nucl Med 2011;10:122.

49. Almen A, Mattsson S. Radiological protection of foetuses and breastfed children of occupationally exposed women in nuclear medicine-challenges for hospitals. Phys Med 2017;43:172-7.

50. Rubio IT, Diaz Botero S, Esgueva A, Rodriguez R, Cortadellas T, Cordoba $\mathrm{O}$, et al. The superparamagnetic iron oxide is equivalent to the Tc99 radiotracer method for identifying the sentinel lymph node in breast cancer. Eur J Surg Oncol EJSO 2015;41:46-51.

51. Davenport MS, Cohan RH, Caoili EM, Ellis JH. Repeat contrast medium reactions in premedicated patients: frequency and severity. Radiology 2009;253:372-9.

52. Khalil M. A snapshot on nuclear cardiac imaging. Egypt J Nucl Med 2017;15:1-5.

53. Silberstein EB. Prevalence of adverse reactions to positronemitting radiopharmaceuticals in nuclear medicine. J Nucl Med 1998:39:2190.

54. Abell TL, Camilleri M, Donohoe K, Hasler WL, Lin HC, Maurer $\mathrm{AH}$, et al. Consensus recommendations for gastric emptying scintigraphy: a joint report of the American neurogastroenterology and motility society and the society of nuclear medicine. J Nucl Med Technol 2008;36:44-54.

55. Babu K, Jayaraaj IA, Prabhakar J. Effect of abnormal thyroid hormone changes in lipid peroxidation and antioxidant imbalance in hypothyroid and hyperthyroid patients. Int J Biol Med Res 2011;2:1122-6.

56. Meier DA, Brill DR, Becker DV, Clarke SE, Silberstein EB, Royal $\mathrm{HD}$, et al. Procedure guideline for therapy of thyroid disease with 131Iodine. J Nucl Med 2002;43:856-61.

57. Düsman E, Berti AP, Mariucci RG, Lopes NB, Vicentini VEP. Mutagenicity of diagnostic and therapeutical doses of radiopharmaceutical iodine-131 in wistar rats. Radiat Environ Biophys 2011;50:579.

58. Bonnema SJ, Hegedüs L. Radioiodine therapy in benign thyroid diseases: effects, side effects, and factors affecting therapeutic outcome. Endocr Rev 2012;33:920-80.

59. Weetman AP. Radioiodine treatment for benign thyroid diseases. Clin Endocrinol (Oxf) 2007;66:757-64.

60. Nielsen OS, Munro AJ, Tannock IF. Bone metastases: pathophysiology and management policy. J Clin Oncol 1991; 9:509-24.

61. Lin A, Ray ME. Targeted and systemic radiotherapy in the treatment of bone metastasis. Cancer Metastasis Rev 2006;25:669-75.
62. Liberal FDG, Tavares AAS, Tavares JMR. Palliative treatment of metastatic bone pain with radiopharmaceuticals: a perspective beyond strontium-89 and Samarium-153. Appl Radiat Isot 2016;110:87-99.

63. Reang P, Gupta M, Kohli K. Biological response modifiers in cancer. Medscape Gen Med 2006;8:33.

64. Leahy MF, Seymour JF, Hicks RJ, Turner JH. Multicenter phase II clinical study of iodine-131-rituximab radioimmunotherapy in relapsed or refractory indolent non-Hodgkin's lymphoma. J Clin Oncol 2006;24:4418-25.

65. Coffey RJ, Flickinger JC, Bissonette DJ, Lunsford LD. Radiosurgery for solitary brain metastases using the cobalt- 60 gamma unit: methods and results in 24 patients. Int J Radiat Oncol Biol Phys 1991;20:1287-95.

66. Fourquet A, Campana F, Mosseri V, Cetingoz R, Luciani S, Labib A, et al. Iridium-192 versus cobalt- 60 boost in 3-7 cm breast cancer treated by irradiation alone: final results of a randomized trial. Radiother Oncol 1995;34:114-20.

67. Nordyke RA, Gilbert FI. Optimal iodine-131 dose for eliminating hyperthyroidism in graves' disease. J Nucl Med 1991;32:411-6.

68. De Klerk JMH, Van Dijk A, Van Het Schip AD, Zonnenberg BA, Van Rijk PP. Pharmacokinetics of rhenium-186 after administration of rhenium-186-HEDP to patients with bone metastases. J Nucl Med 1992;33:646-51.

69. Sangro B, Bilbao JI, Boan J, Martinez Cuesta A, Benito A, Rodriguez J, et al. Radioembolization using 90Y-resin microspheres for patients with advanced hepatocellular carcinoma. Int J Radiat Oncol 2006;66:792-800.

70. Serafini AN. Systemic metabolic radiotherapy with samarium153 EDTMP for the treatment of painful bone metastasis. Q J Nucl Med Mol Imaging 2001;45:91.

71. Lewington VJ, McEwan AJ, Ackery DM, Bayly RJ, Keeling DH, Macleod PM, et al. A prospective, randomised double-blind crossover study to examine the efficacy of strontium-89 in pain palliation in patients with advanced prostate cancer metastatic to bone. Eur J Cancer Clin Oncol 1991;27:954-8.

72. Fettich J, Padhy A, Nair N, Morales R, Tanumihardja M, Riccabonna G, et al. Comparative clinical efficacy and safety of phosphorus-32 and strontium-89 in the palliative treatment of metastatic bone pain: results of an IAEA coordinated research project. World J Nucl Med 2003;2:226-31.

73. Knut L. Radiosynovectomy in the therapeutic management of arthritis. World J Nucl Med 2015;14:10.

74. Kraeber Bodere F, Campion L, Rousseau C, Bourdin S, Chatal JF, Resche I. Treatment of bone metastases of prostate cancer with strontium-89 chloride: efficacy in relation to the degree of bone involvement. Eur J Nucl Med 2000;27:1487-93.

75. Boschi A, Martini P, Pasquali M, Uccelli L. Recent achievements in Tc-99m radiopharmaceutical direct production by medical cyclotrons. Drug Dev Ind Pharm 2017;43:1402-12.

76. Curtis C, Gamez JE, Singh U, Sadowsky CH, Villena T, Sabbagh $\mathrm{MN}$, et al. Phase 3 trial of flutemetamol labeled with radioactive fluorine 18 imaging and neuritic plaque density. JAMA Neurol 2015;72:287-94.

77. Vente MA, de Wit TC, Van Den Bosch MA, Bult W, Seevinck PR, Zonnenberg BA, et al. Holmium-166 poly (L-lactic acid) microsphere radioembolization of the liver: technical aspects studied in a large animal model. Eur Radiol 2010;20:862-9.

78. Maxon III HR, Smith HS. Radioiodsne-131 in the diagnosis and treatment of metastatic weil differentiated thyroid cancer. Endocrinol Metab Clin North Am 1990;19:685-718.

79. Mandel SJ, Shankar LK, Benard F, Yamamoto A, Alavi A. Superiority of iodine-123 compared with iodine-131 scanning for thyroid remnants in patients with differentiated thyroid cancer. Clin Nucl Med 2001;26:6-9.

80. Mohammed A. El-Motaleb, Amal S Farrag, Ismail T Ibrahim, Mona O Sarhan, Magda F Ismail. Preparation and molecular modeling of radioiodopropranolol as a novel potential radiopharmaceutical for lung perfusion scan. Int J Pharm Pharm Sci 2015;7:110-6.

81. Visakh T, Suresh Sukumar, Abhimanyu Pradhan. Estimation of entrance surface radiation dose to thyroid region computed tomography brain examination. Asian J Pharm Clin Res 2019;12:121-3. 
82. Falk RH, Lee VW, Rubinow A, Hood WB, Cohen AS. Sensitivity of technetium-99m-pyrophosphate scintigraphy in diagnosing cardiac amyloidosis. Am J Cardiol 1983;51:826-30.

83. Ebaugh FG, Emerson CP, Ross JF, Aloia R, Halperin P, Richards $\mathrm{H}$. The use of radioactive chromium 51 as an erythrocyte tagging agent for the determination of red cell survival in vivo. J Clin Invest 1953;32:1260-76.

84. Stevens LA, Nolin TD, Richardson MM, Feldman HI, Lewis JB, Rodby $\mathrm{R}$, et al. Comparison of drug dosing recommendations based on measured GFR and kidney function estimating equations. Am J Kidney Dis 2009;54:33-42.

85. Bekerman C, Hoffer PB, Bitran JD. The role of gallium-67 in the clinical evaluation of cancer. Semin Nucl Med 1984; 14:296-323.

86. Zaret BL. Myocardial imaging with radioactive potassium and its analogs. Prog Cardiovasc Dis 1977;20:81-94.

87. Gross GJ, Warltier DC, Hardman HF, Somani P. The effect of ouabain on nutritional circulation and regional myocardial blood flow. Am Heart J 1977;93:487-95.
88. Pineda JD, Lee T, Ain K, Reynolds JC, Robbins J. Iodine-131 therapy for thyroid cancer patients with elevated thyroglobulin and negative diagnostic scan. J Clin Endocrinol Metab 1995;80:1488-92.

89. O'Keefe SJ, Ogden JM, Young GO, Dicker J, Marks IS. Measurement of pancreatic enzyme synthesis in humans. Int J Pancreatol 1989;4:13-27.

90. Tang CW, Maletskos CJ. Elimination of sodium-24 and potassium-42 interferences inactivation analysis of biological samples. Science 1970;167:52-4.

91. Sullivan PJ, Burke WM, Burch WM, Lomas FE. A clinical comparison of Technegas and xenon-133 in 50 patients with suspected pulmonary embolus. Chest 1988;94:300-4.

92. Okayama K, Kurata C, Tawarahara K, Wakabayashi Y, Chida K, Sato A. Diagnostic and prognostic value of myocardial scintigraphy with thallium-201 and gallium-67 in cardiac sarcoidosis. Chest 1995;107:330-4.

93. Hartman AW, Nesbitt Jr RU, Smith FM, Nuessle NO. Viscosities of acacia and sodium alginate after sterilization by cobalt-60. J Pharm Sci 1975;64:802-5. 